\section{Liberación del ion flúor de un cemento de ionómero vítreo modificado con extracto etanólico de propóleo}

\section{Liberation of the fluoride ion from a vitreous ion cement modified with ethanol extract of propolis}

\begin{abstract}
Resumen
Objetivo. El objetivo de este estudio fue cuantificar la liberación de flavonoides y flúor en probetas de ionómero vítreo convencional tipo II modificado con extracto de propóleo. Métodos. Fueron utilizadas 60 unidades de análisis. El extracto etanólico de propóleo al $2 \%$ fue incorporado a un ionómero vítreo tipo II. Para la determinación de la liberación de flavonoides el laboratorio analizó la concentración de quercetina por $\mathrm{ml}$ de solución, sea agua destilada o solución fisiológica durante un periodo de 5 días. Resultados. Hubo liberación inicial de $0,40 \mathrm{mg} / \mathrm{ml}$ de flúor en solución fisiológica y de $0,35 \mathrm{mg} / \mathrm{ml}$ de flúor en agua destilada, y una liberación final de $0 \mathrm{mg} / \mathrm{ml}$ de flavonoides y de flúor en solución fisiológica y de $0,18 \mathrm{mg} / \mathrm{ml}$ de flúor en solución de agua destilada. Conclusiones. La liberación de flúor y flavonoides se produce en mayor concentración en las primeras horas, decreciendo a medida que pasan las horas.
\end{abstract}

Palabras clave: Cementos de ionómero vítreo; Flavonoides; Flúor (fuente: DeCS BIREME).

\begin{abstract}
Objective. The objective of this study was to quantify the release of flavonoids and fluoride in test tubes of conventional type II vitreous ionomer modified with propolis extract. Methods. Sixty units of analysis were used. The $2 \%$ propolis ethanolic extract was incorporated into a type II glass ionomer. To determine the release of flavonoids, the laboratory analyzed the concentration of quercetin per $\mathrm{ml}$ of solution, either distilled water or physiological solution, during a period of 5 days. Results. There was an initial release of $0.40 \mathrm{mg} / \mathrm{ml}$ of fluorine in physiological solution and $0.35 \mathrm{mg} / \mathrm{ml}$ of fluorine in distilled water, and a final release of $0 \mathrm{mg} / \mathrm{ml}$ of flavonoids and fluorine in physiological solution and of $0,18 \mathrm{mg} / \mathrm{ml}$ of fluorine in distilled water solution. Conclusions. The release of fluoride and flavonoids occurs in greater concentration in the first hours, decreasing as the hours go by.
\end{abstract}

Keywords: Glass ionomer cements; Flavonoids; Fluoride (source: MeSH NLM).

\section{Artículo Original}

Melisa Raquel Lezcano 1,a, María Eugenia Zamudio 1,b

${ }^{1}$ Universidad Nacional del Nordeste, Facultad de Odontología, Corrientes, Argentina.

a Magíster en Metodología de la Investigación Científica.

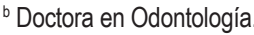

\section{Correspondencia:}

Melisa Raquel Lezcano: mlezcano@odn.unne.edu.ar Barrio Bañado Norte French 2291, Corrientes, Argentina. ORCID: 0000-0003-4368-1902

\section{Coautores:}

María Eugenia Zamudio: maeugeniaz@yahoo.com.ar ORCID: 0000-0003-0813-0048

\section{Editora:}

Rosse Mary Falcón-Antenucci

Universidad Inca Garcilaso de la Vega, Lima, Perú.

Conflicto de intereses: los autores declaran no tener conflictos de interés.

Fuente de financiamiento: Secretaria General de Ciencia y Técnica de La Universidad Nacional del Nordeste.

Recibido: 11/01/21

Aceptado: 09/02/21

Publicado: 01/04/21 


\section{Introducción}

La caries dental es la enfermedad bacteriana que más ha afectado a la cavidad bucal en las poblaciones humanas. La misma es de origen multifactorial en la que existe interacción de tres factores principales: el huésped (higiene bucal, la saliva y los dientes), la microflora (infecciones bacterianas) y el sustrato (dieta cariogénica) ${ }^{1}$.

Uno de los materiales para tratar caries dental mundialmente utilizada en niños es el cemento de ionómero vítreo. Los tejidos cariados se retiran con instrumentos manuales y rotatorios, luego la cavidad resultante, así como las fosas y fisuras adyacentes, se restauran y sellan con un material restaurativo ${ }^{2}$.

Los cementos son materiales dentales que se utilizan en varias disciplinas de la práctica odontológica, los CIV (cemento de ionómero vítreo) se endurecen o fraguan mediante una reacción ácido-base entre su fase vítrea y orgánica. Dentro de las propiedades de este material se encuentra la propiedad anticariogénica. El mecanismo de la acción antibacteriana de los CIV no es claro, se cree que la liberación de iones de flúor es importante, sin embargo, no es el único mecanismo, también puede estar relacionado con la acidez del ácido polialquenoico ${ }^{3}$.

Se postula que diferentes propóleos pueden presentar diferentes propiedades químicas y farmacológicas, por lo tanto, la estandarización de los propóleos es una necesidad ${ }^{4}$. El propóleo es un producto apícola que se destaca por sus propiedades antibacterianas, fungicidas, anestésicas, entre otras de interés odontológico y medicinal. En los últimos años ha aumentado su utilización como medicina natural. Por lo tanto, es un producto valioso y de fácil obtención para la industria farmacéutica, de cosméticos y de alimentos ${ }^{5,6}$.

Dentro de los componentes farmacológicos activos más importantes del propóleo se encuentran los flavonoides y compuestos fenólicos como terpenoides y aromáticos. Dentro de estos últimos la apigenina (flavonoides) y el tt-farnesol (terpenoides) son los que poseen mayores propiedades antimicrobianas. Algunos estudios, afirman que el propóleo no puede difundirse en áreas profundas del diente ya que su efecto sobre los lactobacilos, responsables de la progresión de la caries en áreas profundas, es muy limitado, por cuanto su efectividad es en caries de esmalte o dentina de poca profundidad ${ }^{7,8}$.

El propóleo en afecciones bucales y tratamientos quirúrgicos posee efectos antibióticos, anestésicos, cicatrizantes y de aumento de la respuesta inmune local, para lograr una curación más rápida y menos dolorosa 9 . La combinación de ambos elementos (CIV y Propóleo) podría ser una opción para disminuir la frecuencia de las afecciones bucales en la población, no solo por sus propiedades individuales, sino también por el valor asequible de ambos. Resulta de particular interés, el análisis de la combinación de ambos elementos para encontrar un aliado en el combate de la caries con relación a sus agentes etiológicos, particularmente la flora microbiana bucal. Por lo tanto, el objetivo del presente trabajo es cuantificar la liberación de flavonoides y flúor en probetas de Ionómero vítreo convencional tipo II modificado con extracto de propóleo.

\section{Métodos}

El presente estudio in vitro es de tipo analítico, longitudinal y experimental. Para eso se obtuvo propóleo en bruto de la localidad de San Luis del Palmar (Corrientes, Argentina).

Obtención del propóleo. El método de recolección del propóleo fue por raspado de la colmena, al retirar de los cantos de los marcos del cubre panal o entretapa, o de los lugares en los cuales las abejas depositaron de forma espontánea. Se tomaron las medidas de seguridad necesarias para evitar contaminación, el producto fue almacenado al resguardo de la luz hasta su utilización (figura 1) ${ }^{8,10}$.

La obtención del propóleo está sujeta al componente estacional de producción melífera de la abeja por lo que hay que esperar el tiempo de producción y cosecha. El mismo puede ser cosechado de las explotaciones apícolas como un complemento a otros productos como la miel, la cera, el polen, la jalea real, etc.

El propóleo adquirido se remitió al Laboratorio de Análisis de Productos Apícolas de la Universidad Nacional del Nordeste donde se determinó las propiedades organolépticas y las propiedades físico-químicas, para la determinación de la calidad del mismo, obteniendo así un propóleo libre de metales pesados, insecticidas, bactericidas, antibióticos, agrotóxicos y bacterias.

Las propiedades organolépticas consideradas en la calidad de los productos apícolas como el propóleo, consisten en: aspecto, color, olor, sabor. Las propiedades físico-químicas: humedad, índice de oxidación, presencia de principio activo, en este caso, la quercetina, compuestos fenólicos, mezclas mecánicas y contenido de impurezas mecánicas,

Para el análisis del propóleo crudo se utilizaron las Normas Salvadoreñas (NSO 65.19.02:03) y un patrón de quercetina para realizar la curva de calibración, los resultados fueron expresados como mg de quercetina por cada gramo de propóleo ${ }^{5}$. Actualmente, no existe un método estandarizado para la extracción de los compuestos activos del propóleo, cada laboratorio aplica diferentes técnicas de extracción. Una vez verificada la calidad del propóleo se elaboró un extracto etanólico de propóleo al $2 \%$.

Obtención del extracto de propóleo. Para la obtención del extracto de propóleo al $2 \%$ se tomó $2 \mathrm{~g}$ de propóleo, que fue trozado en pedazos pequeños y colocado en un frasco color caramelo con 11 de etanol $70^{\circ}$, (figura $2 \mathrm{~A}$ ) de tal manera que el solvente cubriera todos los fragmentos del propóleo, protegido de toda fuente de luz, se dejó en maceración a temperatura ambiente (figura 2B), el mismo fue almacenado durante un periodo de 7 días a $37^{\circ} \mathrm{C}$. El frasco se agitó durante los 7 días siguientes durante 40 minutos para lograr la disolución del propóleo en el etanol ${ }^{11,12}$. 


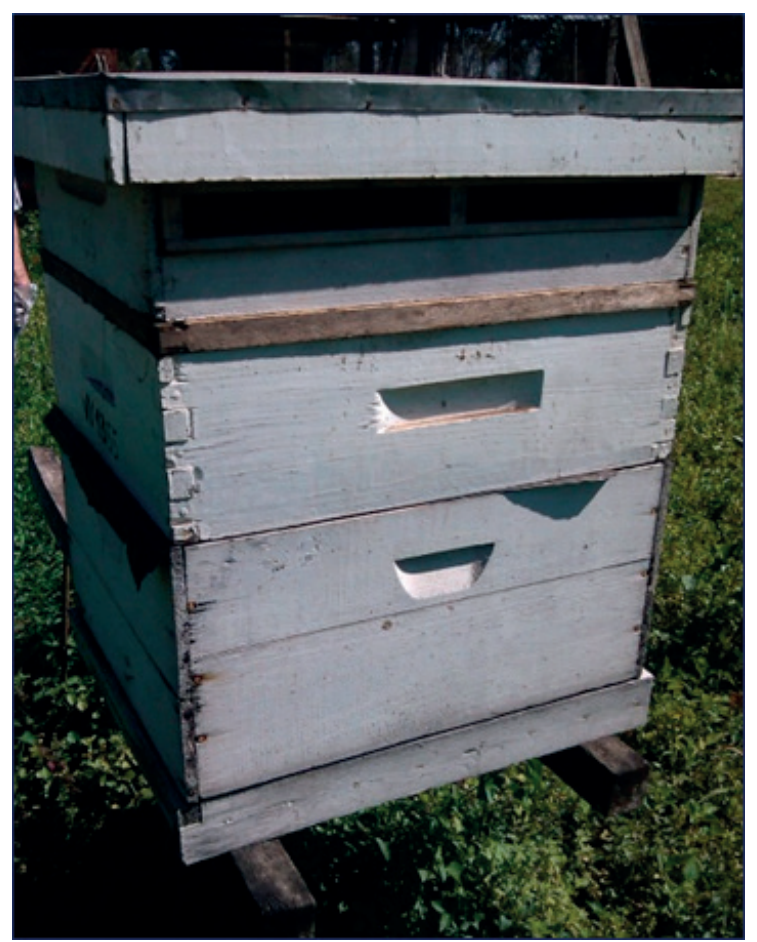

Figura 1. Cajón Colmena donde se realiza el depósito del propóleo

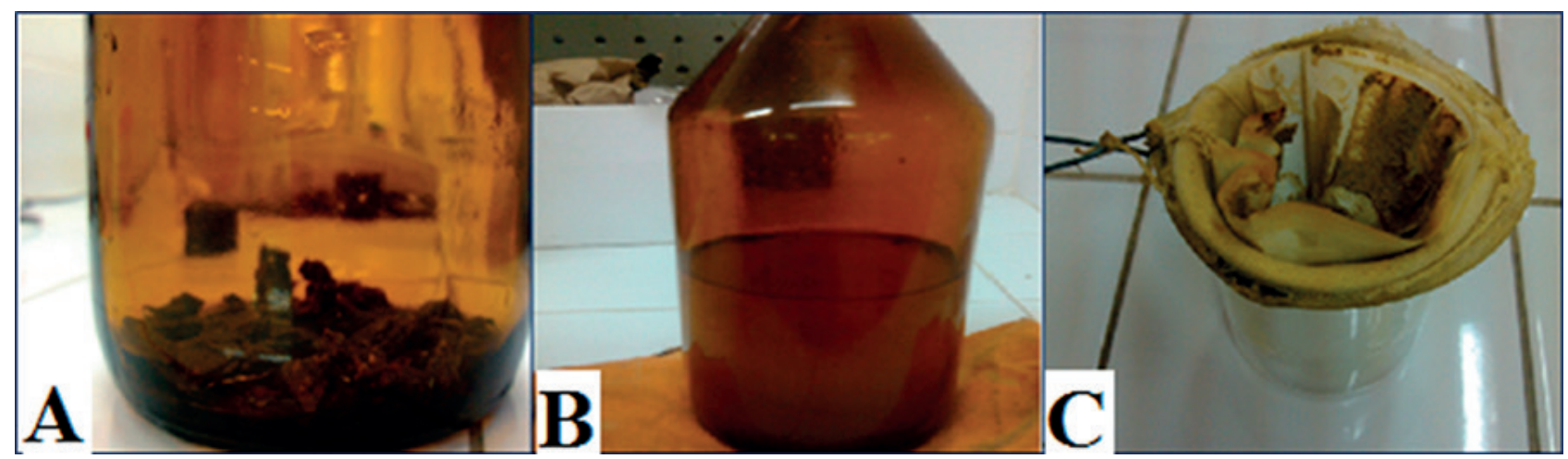

Figura 2. Elaboración del extracto etanólico de propóleo. A. Trozado del propóleo crudo. B. Macerado. C. Filtrado

Posteriormente, pasó al estadio de filtración del extracto en el cual se dejó sedimentar durante 7 días y después pasó por un filtro con la finalidad de eliminar los restos de impurezas o sólidos y el material insoluble en etanol (figura 2C). Se trabajó con la concentración inhibitoria mínima de propóleo por lo que se elaboró una de solución de extracto de propóleo en concentración (CMI) de $83,2 \mathrm{mg} / \mathrm{ml}^{13}$. La concentración mínima inhibitoria (CMI) es definida como la concentración más baja de extracto que es capaz de inhibir el crecimiento celular ${ }^{14}$.

Se confeccionaron 60 probetas como unidades de análisis, siendo divididas en dos grupos: Grupo I con solución fisiológica y Grupo II con agua destilada. Cada grupo se dividió en dos subgrupos A y B: Grupo A (grupo control) y Grupo B (grupo experimental). En el subgrupo A se determinó la liberación de flúor de un ionómero vítreo sin modificar, y en el subgrupo B se determinó la liberación tanto de flúor como de flavonoides de un ionomero vítreo modificado con extracto etanólico de propóleo (tabla 1).

Preparación de las probetas. Para la preparación de las probetas se siguió la norma No 96 de la ADA (Asociación Dental Americana). Para la manipulación del material se siguieron las indicaciones del fabricante ${ }^{15,16}$. Se colocó el material en un tubo conformador de probeta hasta el fraguado. Posteriormente se colocó el tubo en el dispositivo de corte micrótomo o cortadora de precisión de baja velocidad (ISOMETC 11-1280-250, Buehler, Germany) para obtener discos de $1 \mathrm{~cm}$ de diámetro y de $3 \mathrm{~mm}$ de alto, estos discos se colocaron en sus respectivas soluciones.

Estas soluciones fueron cambiadas diariamente durante un periodo de 5 días por una nueva solución de agua destilada. La solución retirada se almacenó a $37^{\circ} \mathrm{C}$ hasta completar los 5 días donde fueron enviadas para el análisis correspondiente (figura 3). 
Tabla 1. Distribución de los grupos de probetas

\begin{tabular}{cccc}
\hline \multicolumn{2}{c}{$\begin{array}{c}\text { GRUPO I (30) } \\
\text { Solución Fisiológica }\end{array}$} & $\begin{array}{c}\text { GRUPO II (30) } \\
\text { Agua destilada }\end{array}$ \\
\hline $\begin{array}{c}\text { Subgrupo A (15) } \\
\text { control }\end{array}$ & $\begin{array}{c}\text { Subgrupo B (15) } \\
\text { experimental }\end{array}$ & $\begin{array}{c}\text { Subgrupo A (15) } \\
\text { control }\end{array}$ & $\begin{array}{c}\text { Subgrupo B (15) } \\
\text { experimental }\end{array}$ \\
\hline$[\%]$ Flúor & {$[\%]$ Flavonoides } & {$[\%]$ Flúor } & [\%] Flavonoides \\
\hline
\end{tabular}

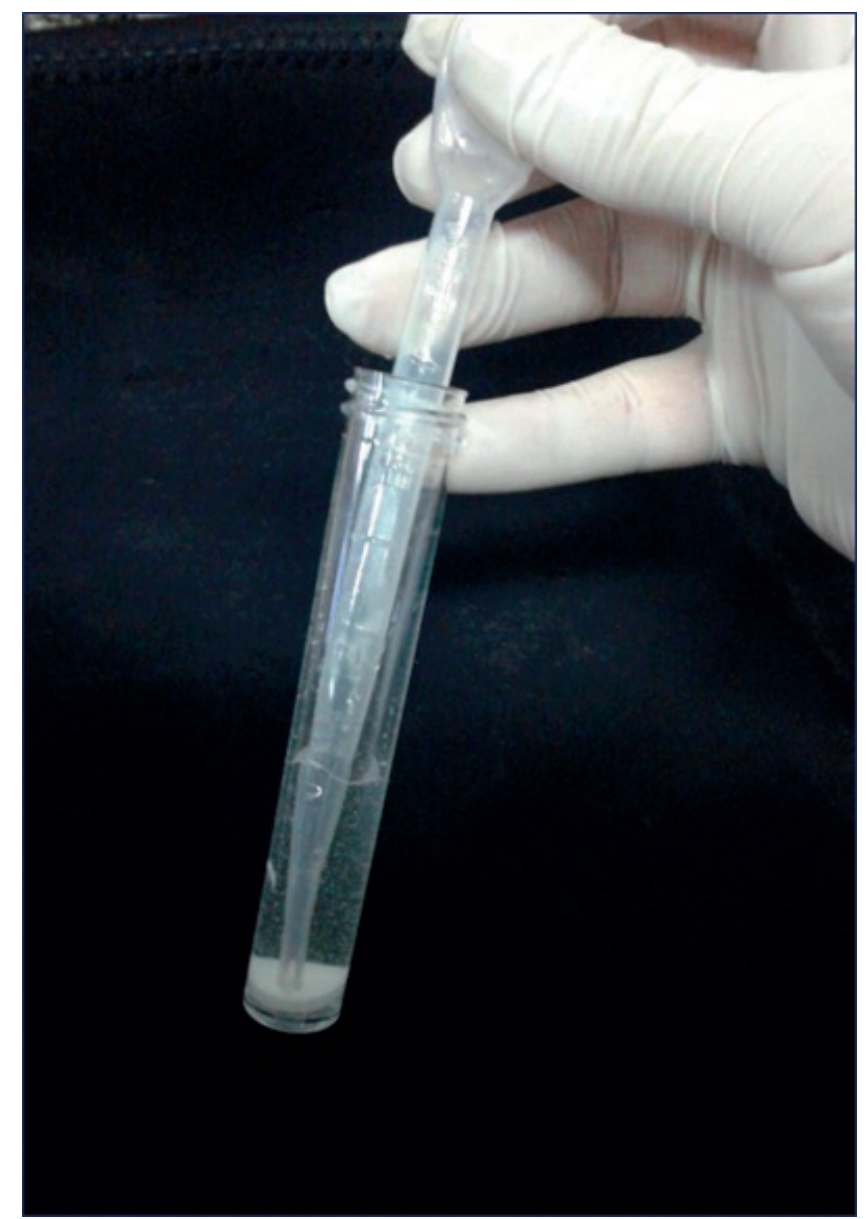

Figura 3. Probeta de cemento de ionómero vítreo en solución fisiológica

Análisis. Para el análisis de la concentración de ión flúor el laboratorio utilizó la Solución de SPANDS (Sal trisódica del ácido 1,8-dihidroxi-2-(4- sulfofenilazo) naftalen-3,6-disulfónico). Para la determinación de la liberación de flavonoides el laboratorio analizó la concentración de quercetina por $\mathrm{ml}$ de solución, sea agua destilada o solución fisiológica.

\section{Resultados}

$\mathrm{Al}$ realizar la incorporación de las probetas en las soluciones, las que se incorporaron a la solución fisiológica mantuvieron su integridad, sin embargo, las que se incorporaron al agua destilada presentaron disolución luego de las primeras $48 \mathrm{~h}$, por lo que, el análisis de la solución de agua destilada solo pudo ser analizada en las primeras $72 \mathrm{~h}$.

$\mathrm{Al}$ analizar la tabla 2, se observa que en todos los grupos la liberación de flúor fue gradual, siendo mayor a las $24 \mathrm{~h}$ y disminuyendo en los días subsiguientes. En la solución fisiológica, el Grupo I - Subgrupo A se obtuvo un promedio de liberación inicial de $0,40 \mathrm{mg} / \mathrm{ml}$ y de $0,35 \mathrm{mg} / \mathrm{ml}$ final a las $72 \mathrm{~h}$, en los días siguientes la concentración fue de $0 \mathrm{mg} / \mathrm{ml}$. Las concentraciones de quercetina fueron: Subgrupo B de $0,10 \mathrm{mg} / \mathrm{ml}$ (inicial) y $0,05 \mathrm{mg} / \mathrm{ml}$ de solución fisiológica (final a las $72 \mathrm{~h}$ ).

En las soluciones de agua destilada el Grupo II subgrupo A obtuvo un promedio de liberación inicial de $0,35 \mathrm{mg} / \mathrm{ml}$ y de $0,18 \mathrm{mg} / \mathrm{ml}$ final a las $120 \mathrm{~h}$. Las concentraciones de quercetina fueron en el análisis inicial del subgrupo B de $0,15 \mathrm{mg} / \mathrm{ml}$ y final a las $72 \mathrm{~h}$ de 0,09 $\mathrm{mg} / \mathrm{ml}$ de solución de agua destilada (tabla 2).

\section{Discusión}

La liberación de fluoruros se produce en mayor proporción en los primeros días decreciendo en concentración a medida que pasa el tiempo, llegando a ser casi nula en los días 4 y 5, fenómeno atribuido a la composición del agua destilada y a la falta de incorporación de flúor 
Tabla 2. Promedio de liberación de flúor y flavonoides por solución

\begin{tabular}{ccccc}
\hline & \multicolumn{2}{c}{ GRUPO I (Solución Fisiológica) } & \multicolumn{2}{c}{ GRUPO II (Agua destilada) } \\
\hline & $\begin{array}{c}\text { Subgrupo A } \\
\text { (control) }\end{array}$ & $\begin{array}{c}\text { Subgrupo B } \\
\text { (experimental) }\end{array}$ & $\begin{array}{c}\text { Subgrupo A } \\
\text { (control) }\end{array}$ & $\begin{array}{c}\text { Subgrupo B } \\
\text { (experimental) }\end{array}$ \\
\hline [\%] Flúor & {$[\%]$ Flavonoides } & [\%] Flúor & [\%] Flavonoides \\
\hline 24 horas & $0,40 \mathrm{mg} / \mathrm{ml}$ & $0,10 \mathrm{mg} / \mathrm{ml}$ & $0,35 \mathrm{mg} / \mathrm{ml}$ & $0,15 \mathrm{mg} / \mathrm{ml}$ \\
48 horas & $0,30 \mathrm{mg} / \mathrm{ml}$ & $0,08 \mathrm{mg} / \mathrm{ml}$ & $0,30 \mathrm{mg} / \mathrm{ml}$ & $0,10 \mathrm{mg} / \mathrm{ml}$ \\
72 horas & $0,35 \mathrm{mg} / \mathrm{ml}$ & $0,05 \mathrm{mg} / \mathrm{ml}$ & $0,30 \mathrm{mg} / \mathrm{ml}$ & $0,09 \mathrm{mg} / \mathrm{ml}$ \\
96 horas & $0 \mathrm{mg} / \mathrm{ml}$ & $0 \mathrm{mg} / \mathrm{ml}$ & $0,25 \mathrm{mg} / \mathrm{ml}$ & $0 \mathrm{mg} / \mathrm{ml}$ \\
120 horas & $0 \mathrm{mg} / \mathrm{ml}$ & $0 \mathrm{mg} / \mathrm{ml}$ & $0,18 \mathrm{mg} / \mathrm{ml}$ & $0 \mathrm{mg} / \mathrm{ml}$ \\
\hline
\end{tabular}

del medio externo, como sucedería en la cavidad oral mediante compuestos fluorados como la pasta dental.

En trabajos de investigación previamente realizados por Delgado et al. ${ }^{17}$ utilizaron probetas realizadas en conformadores y analizaron soluciones en diferentes periodos de tiempo, en el análisis de la liberación de fluoruros que se realizó sobre soluciones de agua destilada.

Delgado et al. ${ }^{17}$ y Beltrán ${ }^{18}$ señalan que estas características del material tienen que ver con la marca, matriz, el relleno, cantidad de fluoruro añadido, proporción polvo-líquido y el proceso de mezcla, además del medio en que se encuentra y denominan efecto burst o chorro, a la liberación masiva de flúor producida en las primeras $24 \mathrm{~h}$, coincidiendo con los resultados obtenidos en el análisis de las soluciones del presente trabajo. Además, la liberación de fluoruros decrece en el segundo día y disminuye gradualmente con el tiempo, resultados que concuerdan con los obtenidos en este estudio. Aunque la cantidad de fluoruro liberado fue similar para ambos CIV, el modificado con extracto etanólico y el correspondiente al grupo control, pueden existir variaciones, según las características mencionadas.

La cantidad necesaria de fluoruro para prevenir y tratar la caries no está documentada. Se asume que el contenido de fluoruro debe ser tan alto como sea posible, pero sin efectos adversos en las propiedades físicas del material ${ }^{17}$. Consideramos que se debe utilizar el mismo parámetro para la incorporación de flavonoides en el CIV considerando no solo las propiedades físicas del material, sino también la solución que se utilizará para el estudio.

Sosa-López et al. ${ }^{19}$ exponen resultados metodológicos similares a los nuestros donde el costo inicial de inversión es bajo y el sistema de reproducción es rentable en lo que refiere a la producción y recolección de propóleo. Sin embargo, para Salmon ${ }^{20}$ a pesar de ser de fácil obtención en la naturaleza, el costo de refinamiento es elevado por lo que encarece la utilización del mismo en el área de salud.

Se considera necesario establecer parámetros de calidad en la recolección de propóleo crudo y en la elaboración de extracto etanólico de propóleo ${ }^{19}$ coincidiendo con lo informado por Peña ${ }^{4}$ y Lozina et al. ${ }^{8}$ sobre estandarizar y caracterizar las técnicas de control de calidad para poder utilizarlos con fines terapéuticos. Para Delgado et al. ${ }^{12}$, la calidad del propóleo está íntimamente ligada a la época de recolección del propóleo y a la metodología utilizada en la recolección. Por lo tanto, existe la necesidad de pruebas adicionales y de investigar en profundidad los efectos biológicos del propóleo, especialmente considerando la variabilidad de su composición ${ }^{4}$.

Otra característica observada en las probetas es la pérdida del brillo característico del CIV lo que manifiesta exteriormente la adhesión a la estructura dentaria, este brillo representa los grupos carboxílicos libres necesarios para la adhesión ${ }^{2}$. No fueron encontrados estudios relatando esta característica.

Basados en los resultados obtenidos se puede concluir que, la liberación de flúor y flavonoides se produce en mayor concentración en las primeras horas, y decrece a medida que pasa el tiempo.

\section{Agradecimiento}

A la Universidad Nacional del Nordeste por poner a disposición sus instalaciones para la realización de este trabajo.

\section{Referencias bibliográficas}

1. Nuñez DP, Garcia BL. Bioquímica de la caries dental. Rev Haban Cienc Med [Internet] 2010 [citado el 10 de diciembre de 2020];9(2):156-66. Disponible en: http://scielo.sld.cu/scielo.php?script=sci_arttext\&pi$\mathrm{d}=$ S1729-519X2010000200004\&lng=es.

2. Tascón J. Restauración atraumática para el control de la caries dental: historia, características y aportes de la técnica. Rev Panam Salud Publica [Internet]. 2005 [citado el 02 de diciembre de 2020];17(2):110-5. Disponible en: http://www.scielosp.org/scielo.php?script=sci_arttext\&pid=S1020-49892005000200007\&lng=pt\&nrm=iso\&tlng=es.

3. Veron MG, Suarez SG, Prado MO. Estudio de los cambios de la composición química de un ionómero vítreo mediante la técnica de PIXE. Matéria (Rio J.) [Internet]. 2018 [citado el 11 de diciembre de 2020];23(2), Disponible en: http://www.scielo.br/scielo.php?script=sci_arttext\&pid=S1517-70762018000200499\&lng=en\&nr$\mathrm{m}=\mathrm{iso}>$.

4. Peña RC. Estandarización en propóleos: antecedentes químicos y biológicos. Cienc Inv Agr [Internet]. 2008 
[citado el 28 de noviembre de 2020];35 (1):17-26, Disponible en: https://scielo.conicyt.cl/scielo.php?scrip$\mathrm{t}=\mathrm{sci}$ _arttext\&pid=S0718-16202008000100002\&ln$\mathrm{g}=\mathrm{es} \& \mathrm{nrm}=\mathrm{iso}$

5. Chaillou LL, Herrera HA, Maidana JF. Estudio del propóleos de Santiago del Estero, Argentina. Ciênc Tecnol Aliment [Internet]. 2004 [citado el 10 de diciembre de 2020];24(1):11-5. Disponible en: http://www.scielo.br/ scielo.php?script=sci_arttext\&pid=S0101.

6. López ER. Optimización de un método de obtención de extracto etanólico de propóleo en base al poder antimicrobiano [tesis de Maestría]. [Valencia]: Universitat Politècnica de València; 2017. 21p.

7. Premoli G, Laguado P, Díaz N, Romero C, Villarreal J, González A. Uso del Propóleo en odontología. Acta Odontol Venez [Internet]. 2010 [citado el 11 de diciembre de 2020];48(2). Disponible en: https://www.actaodontologica.com/ediciones/2010/2/art-23/.

8. Lozina LA, Peichoto ME, Acosta OC, Granero GE. Estandarización y Caracterización Organoléptica y Físico-Química de 15 Propóleos Argentinos. Lat Am J Pharm [Internet]. 2010 [citado el 28 de noviembre de 2020];29(1):102-10. Disponible en: http://sedici.unlp. edu.ar/handle/10915/7877.

9. Quintana JCD. Efectos del propóleos en los tratamientos quirúrgicos y las úlceras bucales. Rev Cubana Estomatol [Internet]. 1996 [citado el 10 de diciembre de 2020];33(1):42-8. Disponible en: http://www.revestomatologia.sld.cu/index.php/est/article/view/2857/1215.

10. Manrique AJ. Actividad antimicrobiana de propóleos provenientes de dos zonas climáticas del estado Miranda, Venezuela. Efecto de la variación estacional. Zootecnia Trop [Internet]. 2006 [citado el 28 de noviembre de 2020];24(1):43-53. Disponible en http://ve.scielo.org/scielo.php?script=sci_arttext\&pi$\mathrm{d}=$ S0798-72692006000100004\&lng=es\&nrm=iso.

11. Huaytalla RMA. Efecto inhibidor in vitro del extracto etanólico de propóleo al 15\% y 30\% frente a cepas de Lactobacillus acidophilus. Rev Estomatol Herediana [Internet]. 2018 [citado el 10 de diciembre de 2020];28(1):36-43. Disponible en: http://www.scielo.org.pe/scielo.php?script=sci_arttext\&pid=S1019-43552018000100005\&lng=es\&nrm=iso

12. Delgado MLA, Andrade JAO, Ramirez CAB. Caracterización fisicoquímica de propóleos colectados en el Bosque La Primavera Zapopan, Jalisco. Rev Mex de Cienc Forestales [Internet]. 2015 [citado el 25 de noviembre de 2020];6(28):74-87. Disponible en: http:// www.scielo.org. $\mathrm{mx} /$ scielo.php?script $=$ sci_arttext $\& \mathrm{pi}$ $\mathrm{d}=$ S2007-11322015000200006\&lng=es\&nrm=iso.
13. Gómez S, Véliz A, Uribe S. Patrón de liberación de flúor in vitro en sellantes fluorados de resina. Rev Clin Periodoncia Implantol Rehabil Oral [Internet]. 2011 [citado el 5 de enero de 2021];4(3):93-6. Disponible en: https://scielo.conicyt.cl/scielo.php?script=sci_arttext\&pi$\mathrm{d}=$ S0719-01072011000300001\&lng=es.

14. Moreno Z, Martínez P, Figueroa J. Efecto antimicrobiano In vitro de propóleos argentinos, colombianos y cubano sobre Streptococcus mutans ATCC 25175. NOVA. 2007;5(7):70-5. DOI: 10.22490/24629448.376.

15. ANSI/ADA specification no. 66 for dental glass ionomer cements. Council on Dental Materials Instruments, and Equipment. J Am Dent Assoc. 1989;119(1):205.

16. Hernández González RG, Moraga RC, Velásquez MC, Gutiérrez FF. Resistencia compresiva vidrio ionómero Ionofil Molar ${ }^{\ominus}$ y Vitremer según tiempo de exposición en saliva artificial. Rev Clin Periodoncia Implantol Rehabil Oral. 2013;6(2):75-7. DOI: 10.1016/S07185391(13)70125-3.

17. Delgado CRM, Ramírez JPO, Yamamoto AN. Liberación de fluoruro de dos cementos de ionómero de vidrio: estudio in vitro. Rev Odont Mex [Internet]. 2014 [citado el 28 de noviembre de 2020];18(2):84-8. Disponible en: http://www.scielo.org.mx/scielo.php?script=sci_arttext\&pid=S1870-199X2014000200002\&lng=es\&tlng=es.

18. Beltrán R. Materiales liberadores de Fluoruros. [tesis de bachiller]. [Lima]: Facultad de Estomatología, Universidad Peruana Cayetano Heredia; 2010, 35p.

19. Sosa-López AA, Cabrera MG, Álvarez MY. Parámetros físicos y características organolépticas de propóleos provenientes de la Provincia de Misiones, Argentina. J Selva Andina Biosph [Internet]. 2017 [citado el 10 de diciembre de 2020];5(1):51-8. Disponible en: http:// www.scielo.org.bo/scielo.php?script=sci_arttext\&pi$\mathrm{d}=$ S2308-38592017000100006\&lng=es\&tlng=es.

20. Salmón VN. El Propóleo, otro recurso terapéutico en la práctica clínica [curso de adaptación al grado]. [Santander]: Departamento de Enfermería, Universidad de Cantabria; 2014.28 p. 